\title{
Parietal Oscillations Code Nonvisual Reach Targets Relative to Gaze and Body
}

\author{
Verena N. Buchholz, Ole Jensen, and W. Pieter Medendorp \\ Radboud University Nijmegen, Donders Institute for Brain, Cognition and Behaviour, NL 6500 HE, Nijmegen, The Netherlands
}

Recent blood oxygenation level-dependent (BOLD) imaging work has suggested flexible coding frames for reach targets in human posterior parietal cortex, with a gaze-centered reference frame for visually guided reaches and a body-centered frame for proprioceptive reaches. However, BOLD activity, which reflects overall population activity, is insensitive to heterogeneous responses at the neuronal level and temporal dynamics between neurons. Neurons could synchronize in different frequency bands to form assemblies operating in different reference frames. Here we assessed the reference frames of oscillatory activity in parietal cortex during reach planning to nonvisible tactile stimuli. Under continuous recording of magneto-encephalographic data, subjects fixated either to the left or right of the body midline, while a tactile stimulus was presented to a nonvisible fingertip, located either to the left or right of gaze. After a delay, they had to reach toward the remembered stimulus location with the other hand. Our results show body-centered and gaze-centered reference frames underlying the power modulations in specific frequency bands. Whereas beta-band activity $(18-30 \mathrm{~Hz})$ in parietal regions showed body-centered spatial selectivity, the high gamma band $(>60 \mathrm{~Hz})$ demonstrated a transient remapping into gaze-centered coordinates in parietal and extrastriate visual areas. This gaze-centered coding was sustained in the low gamma $(<60 \mathrm{~Hz})$ and alpha $(\sim 10 \mathrm{~Hz})$ bands. Our results show that oscillating subpopulations encode remembered tactile targets for reaches relative to gaze, even though neither the sensory nor the motor output processes operate in this frame. We discuss these findings in the light of flexible control mechanisms across modalities and effectors.

\section{Introduction}

In daily life, we frequently reach toward objects in our visual environment. To program these movements, the brain needs to translate the visual object location from gaze-centered coordinates into body-centered, muscle-based motor signals to change the configuration of the limb (Andersen and Cui, 2009; Crawford et al., 2011). We are also able to reach to nonvisual objects, such as tactile and proprioceptive targets, although we do so less frequently. However, the internal transformations for such reaches may be simpler than visually guided reaches because targets are sensed in the same reference frame-body-centered coordinates-that is needed to control the reach (Bernier et al., 2009; Sarlegna and Sainburg, 2009; Tagliabue and McIntyre, 2011).

The posterior parietal cortex (PPC) is involved in reach planning, with responses of single neurons showing signatures of multiple reference frames, including gaze-centered, bodycentered, and intermediate coordinates (Avillac et al., 2005; Chang et al., 2009; McGuire and Sabes, 2009, 2011; MulletteGillman et al., 2009; Chang and Snyder, 2010). This diversity of tuning properties is thought to support flexible processing in various reference frames (Pouget et al., 2002; Deneve and Pouget,

\footnotetext{
Received July 6, 2012; revised Dec. 2, 2012; accepted Jan. 7, 2013.

Author contributions: V.N.B. and W.P.M. designed research; V.N.B. performed research; V.N.B. contributed unpublished reagents/analytic tools; V.N.B. and W.P.M. analyzed data; V.N.B., O.J., and W.P.M. wrote the paper.

Correspondence should be addressed to Verena N. Buchholz, Department of Neurophysiology and Pathophysiology, University Medical Center Hamburg-Eppendorf, Martinistrasse 52, 20246 Hamburg, Germany. E-mail: v.buchholz@uke.de.

DOI:10.1523/JNEUROSCI.3208-12.2013

Copyright $\odot 2013$ the authors $\quad 0270-6474 / 13 / 333492-08 \$ 15.00 / 0$
}

2004). It is less clear, however, which representations are amplified at the population level in sensory-guided reach control.

Recently, blood oxygenation level-dependent (BOLD) recordings suggested that the target modality dictates the reference frame that is deployed in the PPC, switching between a gazecentered reference frame for visually guided reaches and a bodycentered reference frame for proprioceptive reaches (Bernier and Grafton, 2010). However, the BOLD signal, which is related to metabolic demands of the whole neuronal population in a given area, is insensitive to the temporal dynamics of subgroups of neurons within the area, which may operate in different reference frames (Buchholz et al., 2011).

Local field potentials, and the associated electric currents and magnetic fields, reflect these temporal dynamics of neurons. Their spectral power represents the synchronized postsynaptic potentials of groups of neurons. By synchronizing activity within certain frequency ranges, neurons could temporally be organized into functional assemblies, biasing competition between representations in favor of behaviorally relevant representations (Fries, 2005; Womelsdorf and Fries, 2007).

Recently, using magnetoencephalography (MEG), we found evidence for several coexisting reference frames reflected in the modulation of these frequency bands during saccade planning to tactile stimuli (Buchholz et al., 2011). Here, we used MEG to record oscillatory brain activity from human subjects instructed to plan reaches to remembered tactile targets. We tested whether the temporal dynamics of activity in parietal cortex reflect the sensory reference frame (i.e., body-centered) as suggested by BOLD, or whether they also emphasize spatial 
remapping in other reference frames, including gaze-centered coordinates.

Our results show that even in this task, which does not dictate gaze-centered processing at the initial sensory level or at the final motor stage, tactile stimuli are not only coded in body-centered beta-band oscillations but are also readily remapped into gazecentered coordinates in the gamma and alpha bands in parietal regions. We will discuss these findings from a network perspective, where multiple cortical regions operate in concert via synchronization principles.

\section{Materials and Methods}

Participants. Twenty-two subjects (age range, 20-34 years; 5 female; all right handed), free of any known sensory, perceptual, or motor disorders, volunteered to participate in the experiment. All subjects provided written informed consent according to institutional guidelines of the local ethics committee (Committee on Research Involving Human Subjects, Region Arnhem-Nijmegen, The Netherlands).

Setup. Participants sat in the MEG system that was placed in a magnetically shielded room. They viewed a stimulus device (Fig. 1), located at a distance of $32 \mathrm{~cm}$ from the eyes, with a comfortable, slightly downward gaze direction. The stimulus device (Fig. $1 A$ ) was equipped with a set of fiber optic lights (Omron e3x-na, GB) and piezoelectric Braille stimulators (Metec). Lights at $18^{\circ}$ eccentricity served as visual fixation points. The sensing hand was placed on the device such that each fingertip, except the thumb, overlaid a piezoelectric Braille stimulation pin. A tactile stimulus was presented by transiently raising a pin $\sim 2 \mathrm{~mm}$ for $20 \mathrm{~ms}$, and then lowering it again. To mask the sound generated by the Braille stimulation, subjects wore pneumatic earphones with auditory white noise, adjusted such that its amplitude level was well above the subject's perceptual threshold. The starting position of the reaching hand was symmetrical to the position of the stimulus hand, but slightly elevated in the vertical direction. As the task was performed in complete darkness, except for the fixation point, both hands were nonvisible to the subject. Visual and tactile stimuli were controlled using Presentation 12.2 software (Neurobehavioral Systems).

MEG data were recorded continuously using a whole head system with 275 axial gradiometers (Omega 2000, CTF Systems). Head position was measured using localization coils fixed at anatomical landmarks (nasion, and left and right ear). Horizontal and vertical electrooculograms (EOGs) were recorded and continuously inspected during the experiment. MEG and EOG signals were low-pass filtered at $300 \mathrm{~Hz}$, sampled at $1200 \mathrm{~Hz}$, and then saved to disk. Structural full-brain MRIs were acquired with a $1.5 \mathrm{~T}$ Siemens Sonata scanner using a standard T1weighted scan sequence (flip angle $=15^{\circ}$; voxel size, $1.0 \mathrm{~mm}$ in-plane, $256 \times 256,164$ slices, $\mathrm{TR}=760 \mathrm{~ms} ; \mathrm{TE}=5.3 \mathrm{~ms})$. Anatomic reference markers on these scans served the alignment of the MEG and MRI coordinate systems.

Experimental paradigm. Subjects performed a delayed-reach task with tactile stimuli (Fig. 1A). Each trial began with the simultaneous presentation of two brief tactile pulses, spatially congruent with the fixation light at the location of the tip of the ring finger of the stimulated hand. This initial presentation of spatially congruent visual and tactile stimuli was used to prevent drift in the proprioceptively sensed position of the unseen, stimulated hand in the dark. Subjects were instructed to fixate at the light for the total duration of each trial.

Then, after a baseline period of $1500 \mathrm{~ms}$, a tactile stimulus was delivered to either the index finger or the little finger (Fig. $1 A$, green or blue circles). This was followed by a memory delay of $3000 \mathrm{~ms}$. Subsequently, the fixation light briefly disappeared $(50 \mathrm{~ms})$, instructing the subject to reach with the other hand toward the remembered location of the tactile target, while still maintaining fixation. Then, $2.5 \mathrm{~s}$ after the go cue, the next trial started by two brief flashes of the fixation light.

Subjects performed eight blocks of 80 trials each, in which target locations were pseudo-randomly interleaved. Left and right arm trials were done in different blocks, counterbalanced across subjects. Each trial lasted for $7 \mathrm{~s}$. A brief rest was provided between the blocks during which the subjects could move their hands and eyes freely.
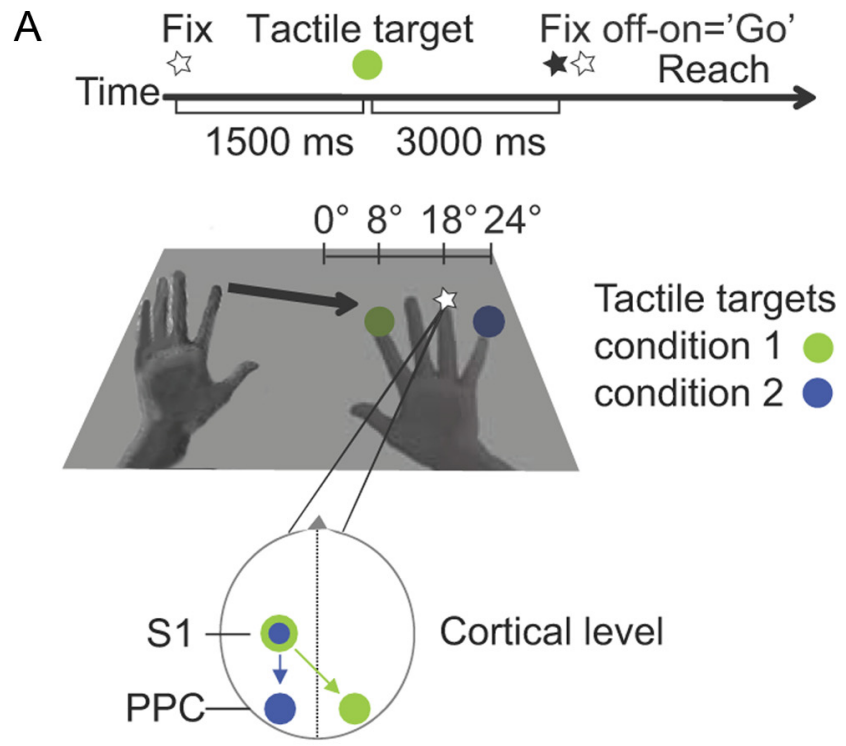

B

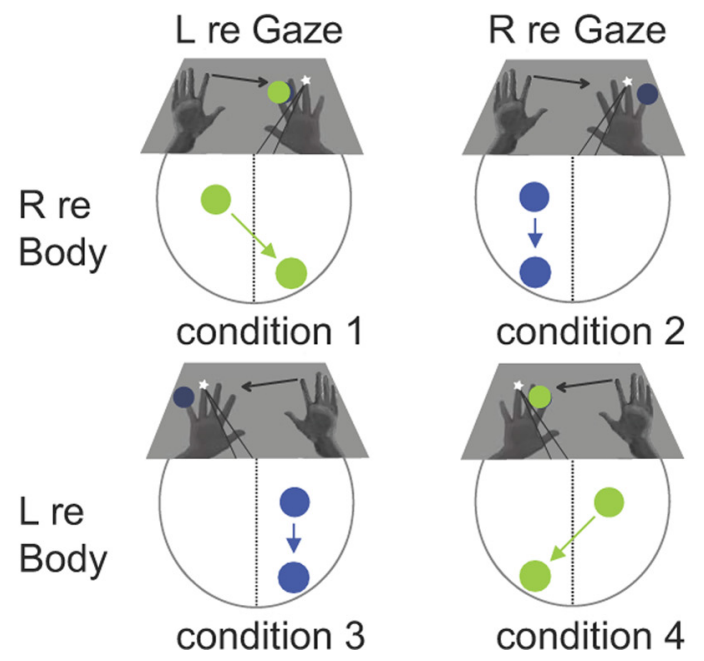

Figure 1. Experimental design. $\boldsymbol{A}$, Task and stimulus sequence. During each block, subjects fixated at dim light above the position of the tip of the ring finger of the right or left hand in a dark environment. A double flash of the fixation light indicated the start of the next trial. After a baseline period of $1.5 \mathrm{~s}$, the tactile target was presented to either the index or little finger of the same hand. After a fixed delay of $3 \mathrm{~s}$, the visual fixation light was switched off for $20 \mathrm{~ms}$, instructing the subject to make a reach to the felt location of the tactile target, while keeping fixation. $\boldsymbol{B}$, Reference frames were probed with a $2 \times 2$ factorial design, with factors side (left vs right relative to) and reference frame (gaze vs body). Body-centered lateralization characterizes the power differences for stimuli delivered to the contralateral versus ipsilateral hand. Gaze-centered selectivity compares the power for nonvisible tactile targets in the contralateral versus ipsilateral visual field. Note, for reach planning, the brain needs to compute the reach vector by comparing the target representation (i.e., desired hand position) and the representation of initial hand position, with both defined in the same frame.

Figure $1 A$ illustrates the two conditions in which the left hand reaches to a tactile stimulus on the right hand, located either to the left or right of fixation. Thus, whereas the hand of stimulation was known beforehand (left or right hand), the gaze-centered location (i.e., visual hemifield) of the tactile stimulus could not be anticipated.

Together, the location of the tactile target defined four conditions, which were organized into a $2 \times 2$ design with side (left vs right) and reference frame (gaze vs body) as factors (Fig. 1B). The location of the tactile target could be represented as left (hand) or right (hand) to the body, the difference in spatial tuning defined as body-centered lateralization. The location of the tactile target could also be represented as left or right (side) from the gaze line, the difference probing gaze-centered lateralization. Thus, by exploiting hemispheric lateralization, we can distin- 
guish between gaze- and body-centered reference frames in the regions that are involved in planning tactile reaches.

Two clarifying notes about this reference frame analysis should be added. First, the analysis does not depend on showing full-field topography: simply exploiting left-right topography (i.e., laterality) already allows for distinguishing between body and gaze-centered coding of the target location (for a similar approach, see Medendorp et al., 2003; Merriam et al., 2003; Bernier and Grafton, 2010). Second, because arms, head, and body are fixed during the experiment, the body-centered reference frame can be treated as equivalent to a head, trunk, or spacecentered reference frame. Different initial arm positions (e.g., using crossed hands) or head position would allow further distinguishing of the reference frames underlying the body-centered activation, but this is outside the scope of this study.

Eye movement analysis. We first inspected trial-based variance of the EOG channels for all conditions together and removed outliers. Furthermore, trials in which participants broke fixation or blinked during a trial were excluded. On average, $127 \pm 21$ of 160 trials per conditions were included into the analysis. The number of rejected trials did not differ among conditions $(p<0.05)$. To exclude a possible eye position bias of the remaining trials during the task, we compared EOG traces during the delay interval $(0.05-3 \mathrm{~s})$ for conditions with targets in the left versus the right hemifield. Neither eye positions during the delay period $(0.05-3 \mathrm{~s})$ nor during the $1 \mathrm{~s}$ interval following the go cue (3-4s) differed significantly (paired $t$ test, $p>0.05$ ).

$M E G$ data analysis. Open source FieldTrip software (Oostenveld et al., 2011) was used to analyze the MEG data, converted into planar field gradients (Bastiaansen and Knösche, 2000). Data were downsampled to 100 and $200 \mathrm{~Hz}$ for low-frequency and high-frequency power analyses, respectively. Time-frequency representations (TFRs) were computed based on a Fourier approach, applying a sliding window, with neighboring time points temporally segregated by $50 \mathrm{~ms}$. We analyzed separately two frequency ranges $(2-40$ and $40-100 \mathrm{~Hz})$ to optimize the time-frequency resolution. The lower frequencies were analyzed with a sliding window of $500 \mathrm{~ms}$ and a Hanning taper. This resulted in a spectral smoothing of $\sim 3 \mathrm{~Hz}$, which allows to capture the typically narrow band effects in the lower frequency range. We applied a multitaper approach (Percival and Walden, 1993) to characterize the broad-band oscillatory activity in high-frequency ranges, reducing spectral leakage. More specifically, the higher frequencies $(30-100 \mathrm{~Hz})$ were analyzed using a sliding window of $400 \mathrm{~ms}$ and 11 orthogonal Slepian tapers. This resulted in a spectral smoothing of $\sim 14 \mathrm{~Hz}$. Gamma-band activity was further analyzed separately for low-frequency $(40-60 \mathrm{~Hz})$ and high-frequency $(60-90 \mathrm{~Hz})$ ranges.

The piezoelectrical stimulation induced short-lived $(50 \mathrm{~ms})$ artifacts in the MEG signals, as reported by Buchholz et al. (2011). As a result, only spectral analyses with analysis windows centered from $300 \mathrm{~ms}$ after stimulus and onward can be considered to be artifact free. We predefined the sensory response interval for the higher frequencies to a $400 \mathrm{~ms}$ window centered at $300 \mathrm{~ms}$ after stimulus onset. Sustained effects were tested for the half and full delay periods. These were defined as the periods between 300 and $1500 \mathrm{~ms}$ and between 300 and $2700 \mathrm{~ms}$ after stimulus onset, respectively, the latter excluding contamination of the motor response (starting at $t=3000 \mathrm{~ms}$ ). For the lower frequency bands, we used a 500 $\mathrm{ms}$ window. Frequency bands of interest were defined as follows based on previous studies: alpha band, $10 \mathrm{~Hz}$; beta band, $18-30 \mathrm{~Hz}$; low gamma band, 40-60 Hz; and high gamma band, 60-90 (Van Der Werf et al., 2010; Buchholz et al., 2011; Uhlhaas et al., 2011).

Task-related power and statistical inferences. We computed task-related changes in power in the various frequency bands relative to average power in the baseline period (Fig. 1A). The baseline power was computed over a $400 \mathrm{~ms}$ (higher frequencies) or $500 \mathrm{~ms}$ (lower frequencies) time window centered $300 \mathrm{~ms}$ before the presentation of the stimulus. For each condition, we expressed the difference in log-power between the delay period and the baseline as a $t$-score, separately for each subject. The $t$-scores were transformed into $z$-scores, as in Medendorp et al. (2007). The resulting $z$-scores, which are well normalized for intrasubject variance, cannot be interpreted as a statistical test outcome, but serve as inputs for the group-level analysis. Significance at the group level was assessed by means of a randomization procedure. We randomly multiplied each individual $z$-score by 1 or by -1 and summed it over subjects. Multiplying the individual $z$-score with +1 or -1 corresponds to permuting the original conditions in that subject. This random procedure was repeated 1000 times to obtain the randomization distribution for the group-level statistic. The proportion of values in the randomization distribution exceeding the test statistic defined the Monte Carlo significance probability, which is also called a $p$ value (Nichols and Holmes, 2002; Maris and Oostenveld, 2007). This random-effects approach solves the multiple-comparisons problem by reducing multiple test statistics to just one aggregate test statistic (for further details about this approach, see Van Der Werf et al., 2008, 2010). We carefully checked that activity in a particular frequency band was not the result of a "bleed in" from another band.

Following Buchholz et al. (2011), body- and gaze-centered selectivity in various frequency bands was assessed by comparing spectral power in conditions with different hands being stimulated and in conditions in which the tactile target is located in opposite directions from the gaze line, respectively. We contrasted the power changes for contralateral versus ipsilateral target locations (defined in either of the two reference frames) for each hemisphere (Fig. $1 B$ ). For a better signal-to-noise ratio, we then pooled these spatially selective effects in hemispheric activation, yielding the body- and gaze-centered laterality across hemispheres. Significant sensor clusters were determined for each of these contrasts, based on the predefined time-frequency tiles.

To localize the neural sources of the spectral components of interest, we applied an adaptive spatial filtering (or beam-forming) technique (i.e., Dynamic Imaging of Coherent Sources) (Gross et al., 2001; Liljeström et al., 2005). Data were organized in MNI coordinates for each subject. For every single subject, the source power was estimated per condition and expressed as $z$-scores relative to the same baseline interval that was used for the sensor-level analysis. The source reconstruction was tuned to peak power values in the same time interval. For plotting, source activity was pooled across hemispheres, and shown on a standard left hemisphere.

\section{Results}

Using a $2 \times 2$ factorial design, we distinguished between gazeand body-centered reference frames underlying the hemispheric lateralization of power in various frequency bands during reach planning to remembered tactile stimuli (Fig. 1B). Body-centered lateralization characterizes the power differences for stimuli delivered to the contralateral versus ipsilateral hand. Gaze-centered lateralization compares the power for nonvisible targets in the contralateral versus ipsilateral visual hemifield.

We tested the hypothesis that the brain exploits not only a body-centered reference frame, but also a gaze-centered reference frame during reach planning to tactile targets, even though neither the initial sensory processing of the target nor the motor output representation dictates the use of this frame.

\section{High-gamma-band activity shows transient encoding in a gaze-centered reference frame}

We first describe the high-frequency power modulations during the sensory response interval. The left-hand panels of Figure 2, A and $B$, show the scalp topographies (pooled across hemispheres) of significant body-centered and gaze-centered selectivity of power in the high gamma range $(60-90 \mathrm{~Hz})$ in response to tactile stimulation (300 ms after stimulus onset). Data are expressed as $z$-scores pooled across subjects; significant sensor clusters $(p<$ 0.05 , controlled for multiple comparisons) are marked by circles. Contralateral increases are color coded using warmer (red) hues; ipsilateral increases are depicted in cooler (blue) hues. As shown, a cluster of sensors overlaying central regions exhibits bodycentric selectivity, as evident in more synchronization contralateral than ipsilateral to the stimulated hand (Fig. $2 A$ ), which is in 
A

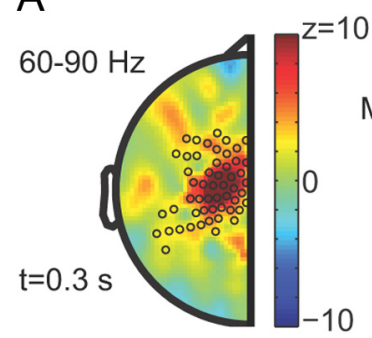

B

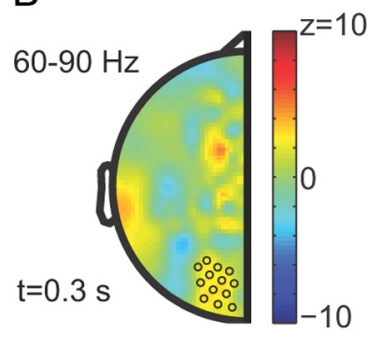

Body-centered

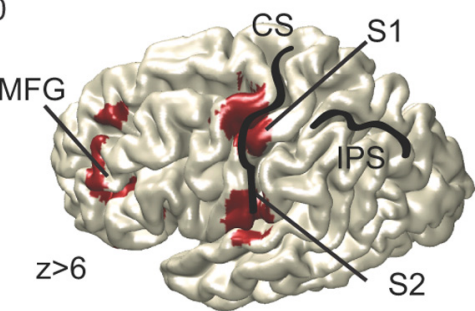

Gaze-centered

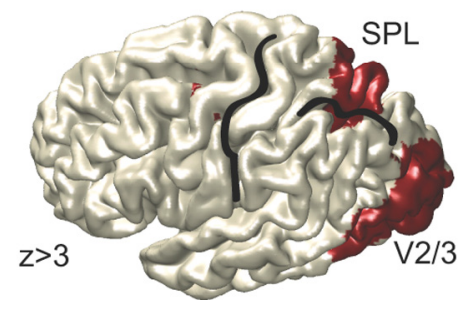

Figure 2. A, Stimulus-induced high-gamma-band activity $(60-90 \mathrm{~Hz})$ shows selectivity in both reference frames. Left, Scalp topography of the body-centered gamma-band power during the sensory response period, pooled across hemispheres $(t=0.3 \mathrm{~s})$. Significant sensor clusters are indicated by circles. Right, Source reconstruction of the body-centered highgamma-band activity during the sensory response period $(60-80 \mathrm{~Hz} ; t=0.3)$. S1, Primary somatosensory areas; $\mathrm{S2}$, secondary somatosensory areas; MFG medial frontal gyrus. Color format: warmer (red) colors increase for targets to contralateral hand; cooler (blue) colors, increase for ipsilateral targets. $\boldsymbol{B}$, Transient gaze-centered high-gamma-band power. Left, Topography of gaze-centered gamma-band power $(60-90 \mathrm{~Hz} ; t=0.3)$ during the sensory response period. Source reconstruction of the transient high-gamma-band response $(60-80 \mathrm{~Hz}$; $t=0.3)$. V2/3, Extrastriate visual areas. Color format: warmer (red) colors, increase for tactile targets in contralateral visual field; cooler (blue) colors, increase for ipsilateral targets.

line with sensory (body-centered) encoding schemes of somatosensory areas. Source localization suggests that these power modulations originate in the primary and secondary somatosensory areas, as well as from prefrontal regions.

Importantly, even though the targets were nonvisible, in these high frequencies we also found gaze-centered gamma-band activity. In other words, gamma-band power was higher for the nonvisible tactile stimulus in the contralateral than the ipsilateral visual hemifield (Fig. 2B). This gaze-centered selectivity, which was seen at posterior sensors, originated from the multisensory superior parietal lobe (SPL), known to be involved in reach computations, and perhaps more surprisingly, from extrastriate visual areas. Thus, these results show that tactile reach targets induce gamma-band oscillations in a gaze-centered reference frame, encoding reach targets relative to gaze, although neither the arrival of the stimulus nor the departure of the motor output is in this frame.

\section{Sustained low-gamma-band and early-delay alpha-band activity show gaze-centered processing}

Subsequently, we investigated whether the observed gazecentered effects are sustained during the delay period, when subjects are planning the reach. Figure $3 A$ shows a significant increase of low-gamma-band activity at posterior sensors contralateral to the hemifield of stimulation. Note that this activity is slightly shifted anterior compared with Figure $2 B$. The time-frequency representation of the power changes, depicted in Figure $2 B$ in addition to the topography plot, demonstrates the sustained gaze-centered effects in the low gamma band at these sensors. Figure $3 A$, bottom panels, shows the source reconstruction

of all gaze-centered modulations at different time points within this frequency range, at 300, 400, 1000, 2000, and $2700 \mathrm{~ms}$ after stimulus offset. As shown, the gaze-centered activity in the low gamma band originates from areas such as the SPL, the ventral premotor cortex and the intraparietal sulcus (IPS), all of which have been implicated in reach planning (Graziano et al., 1997; Snyder et al., 1997, 2000; Astafiev et al., 2003; Pesaran et al., 2006; Breveglieri et al., 2008; Andersen and Cui, 2009; Chang et al., 2009; Filimon et al., 2009; Bernier and Grafton, 2010; Chang and Snyder, 2010; Bansal et al., 2012). In the beginning and toward the end of the delay, secondary somatosensory cortex also shows gaze-centered gamma-band effects.

At parietal sensors, we further found gaze-centered power suppression in the alpha band, most prominently during the first half of the delay period, as depicted in the topographic representation in Figure $3 B$, with the same color coding as in previous figures. The TFR averaged across these sensors indicates that this suppression becomes less prominent toward the end of the delay period. The early gaze-centered power suppression originates from the posterior parietal cortex. Interestingly, $400 \mathrm{~ms}$ after stimulus onset, a second source of gaze-centered alpha-band activity was observed at the intersection of the intraparietal and postcentral sulcus.

\section{Sustained body-centered beta-band modulations in central and posterior regions}

Recall that our design allowed subjects to anticipate the hand of stimulation, but not the side of stimulation relative to gaze. Previous studies have shown beta-band suppression contralateral to the hand of stimulation (the sensing hand), in anticipation of the tactile stimulus (Buchholz et al., 2011; van Ede et al., 2011). Here we corroborated these findings in an analysis without prestimulus baseline correction. The topographic plot of Figure $4 A$, representing the difference in beta-band power $300 \mathrm{~ms}$ before stimulation for contralateral versus ipsilateral stimulation, shows a relative suppression contralateral to the sensing hand at all fronto-central sensors. This difference was also observed in the alpha band (data not shown). With a focus on central sensors (as shown in Fig $2 A$ ), this power difference between contralateral and ipsilateral stimulation became apparent again at $\sim 300 \mathrm{~ms}$ after stimulation and appears to reverse toward the end of the delay. Two functional processes presumably contribute to the lateralization dynamics: stimulus processing at the sensing hand and reach preparation of the other hand. To disentangle these two processes, we examined the power changes during the sensory response and delay intervals, separately for each hemisphere. We present the results such that the left hemisphere is contralateral to the sensing hand (thus, data from left hand stimulation was flipped). Conversely, the right hemisphere shows activation contralateral to the reaching hand. The result, plotted in Figure $4 B$, shows a significant suppression relative to baseline (baseline $t=-0.3$ ) contralateral to the reaching hand and a rebound contralateral to the sensing hand in both the beta (Fig. $4 B$, top) and the alpha range (Fig. $4 B$, bottom). Figure $4 C$ shows the respective TFRs. Next, we reconstructed the beta-band sources, shown in Figure $4 D$. Relative to prestimulus baseline, power increases in primary somatosensory regions contralateral to the sensing hand, whereas beta-band power is suppressed in premotor, primary motor, and posterior parietal cortex contralateral to the reaching hand. The beta decrease is strongest in motor cortex. Furthermore, bilateral dorsolateral prefrontal cortices show an increase in beta-band activity during the delay period. For illustrative purposes, we projected both types of modulations onto one hemi- 


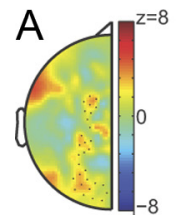

$40-60 \mathrm{~Hz} \mathrm{t}=0.3-2.7 \mathrm{~s}$
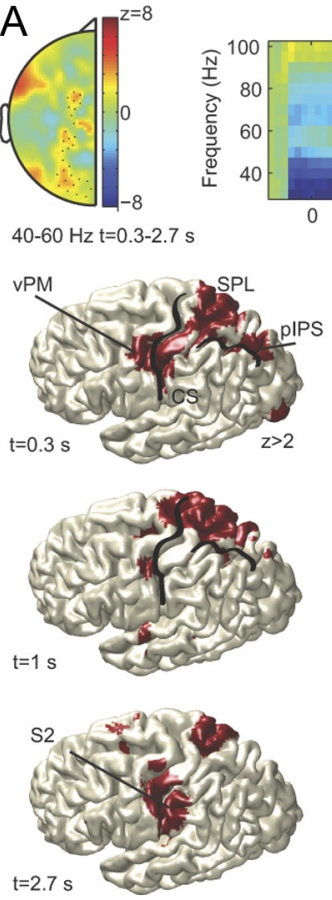

Low Gamma $(40-60 \mathrm{~Hz})$
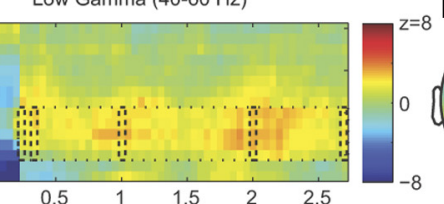

$$
\text { Time (s) }
$$

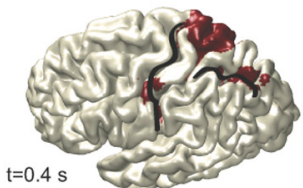

$10 \mathrm{Hzt}=0.3-1.5 \mathrm{~s}$

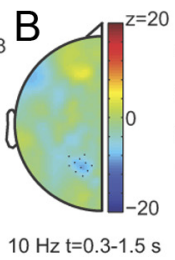

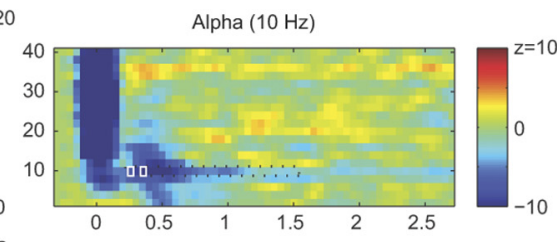
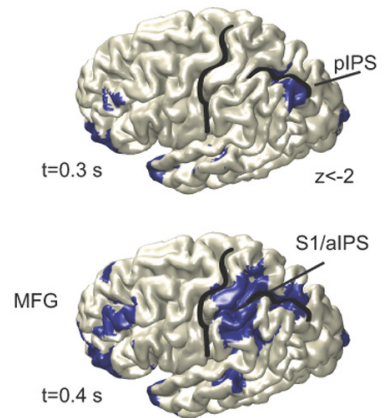

$t=2 s$

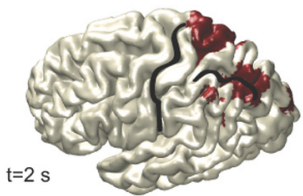

Figure 3. Sustained low-gamma-band activity $(40-60 \mathrm{~Hz})$ and alpha-band $(10 \mathrm{~Hz})$ suppression in gaze-centered coordinates. $A$, Left, Scalp topography averaged across the full delay interval shows gamma power increase at parieto-frontal sensors $(t=0.3-2.7 \mathrm{~s})$. Right, Time-frequency resolved power changes for marked sensors. Bottom, Source reconstruction of the gaze-centered low-gamma-band response $(40-60 \mathrm{~Hz} ; t=0.3 / 0.4 / 1 / 2 / 2.7 \mathrm{~s}) . B$, Left, Scalp topography averaged across the first half of the delay interval shows alpha power suppression at parietal sensors $(t=$ $0.3-1.5 \mathrm{~s}$ ). Right, Time-frequency resolved power changes for marked sensors. Bottom, Source reconstruction of the gaze-centered alpha-band suppression (10 Hz; $t=0.3 / 0.4 \mathrm{~s})$. vPM, Ventral premotor cortex; p/aIPS, posterior/anterior IPS; S2, secondary somatosensory cortex. MFG, middle frontal gyrus.

sphere, ignoring the direction of change relative to baseline. Figure $4 E$ plots the results, showing all sources of body-centered beta-band modulations, including rolandic and parietal regions. The peak of this activity was found at the intersection of S1 and intraparietal sulcus (white circle). We did not find any sustained gaze-centered modulations in the beta band $(p>0.05)$.

\section{Discussion}

We recorded human oscillatory activity during delayed reaches in the dark toward tactile stimuli delivered to the nonreaching hand. We found not only body-centered beta-band oscillations, but also remapped, gaze-centered alpha and gamma-band oscillations in extrastriate regions, even though neither the initial sensory nor the motor output processes operate in this frame. These results support the hypothesis that operations in different reference frames have dissociable spectral dynamics, reflecting distributed parallel processing during reach planning. We will now discuss our findings.

A recent study by Bernier et al. (2010), decoding reference frames by means of BOLD-fMRI, indicated that a part of PPC (SPL) flexibly switches reference frames to match the reference frame of the sensory modality. The authors showed that reach planning to proprioceptive targets is predominately associated with body-centered processing in the PPC, while visually guided reaching is accompanied by gaze-centered parietal processing. Our data, which are not in disagreement with this notion, show a more fine-grained picture based on the frequency contents of signal processing in the reach network. We observed evidence for both reference frames-body (sensory) and gaze (nonsensory) frames-in various frequency bands during reach planning to tactile targets. Whereas BOLD activity represents the overall metabolic demand of neuronal populations, we found evidence for modulations in a nonsensory reference frame in the gamma and alpha bands, but not in the beta band. Because the relationship between the frequency of synchronization and BOLD is rather complex (Logothetis, 2002, 2007; Nir et al., 2007; Conner et al., 2011; Magri et al., 2012) and region dependent (Scheeringa et al., 2011), it is difficult to directly compare our results to the BOLD findings.

Do our results simply reflect eye movement preparation? In natural situations, a reaching movement toward a target is typically accompanied by a movement of the eyes to the same goal. The present study, however, was restricted to reaching with the eyes keeping fixation. Furthermore, behavioral analysis confirmed that there were no eye position biases. One could also argue that subjects planned both eye and arm movements, with the eye movement plan cancelled at the moment of execution. In this perspective, we recently performed experiments that explicitly dissociate eye movement planning from reaching movements (Van Der Werf et al., 2010). The present results show gammaband activation in areas that overlap with the reach-specific areas by that study, ruling out that eye movement preparation drives the present results.

What is the benefit of gaze-centered processing during tactile reaches? An obvious reason is that the fronto-parietal reach network has specialized in visually guided reaching, and therefore operates by default in a gaze-centered reference frame (Darling et al., 2007; Fernandez-Ruiz et al., 2007). Indeed, many brain regions involved in eye-movement control are also activated by reaching and vice versa (Snyder et al., 2000; Levy et al., 2007; Hagan et al., 2012). Recently, it has been shown that both eye position and hand position modulate activity in PPC (Chang et al., 2009), suggesting a role for reference frame transformations between gaze- and bodycentered representations in this area. Therefore, a gaze-centered 
A
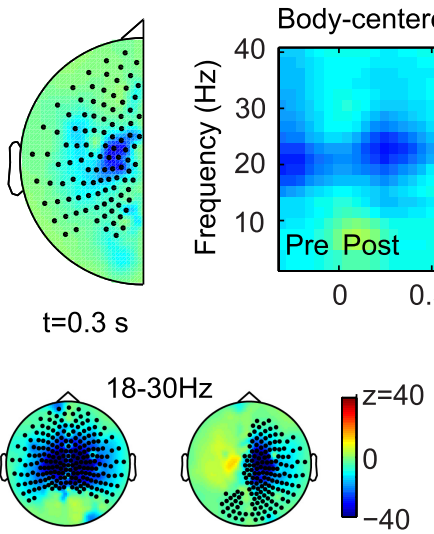

$\mathrm{t}=0.3-2.7 \mathrm{~s}$

$\mathrm{t}=0.3 \mathrm{~s}$

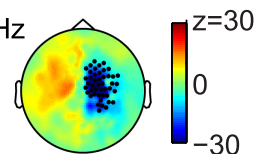

D

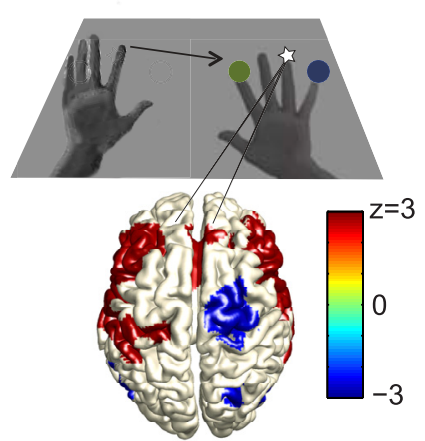

$\mathrm{E}$
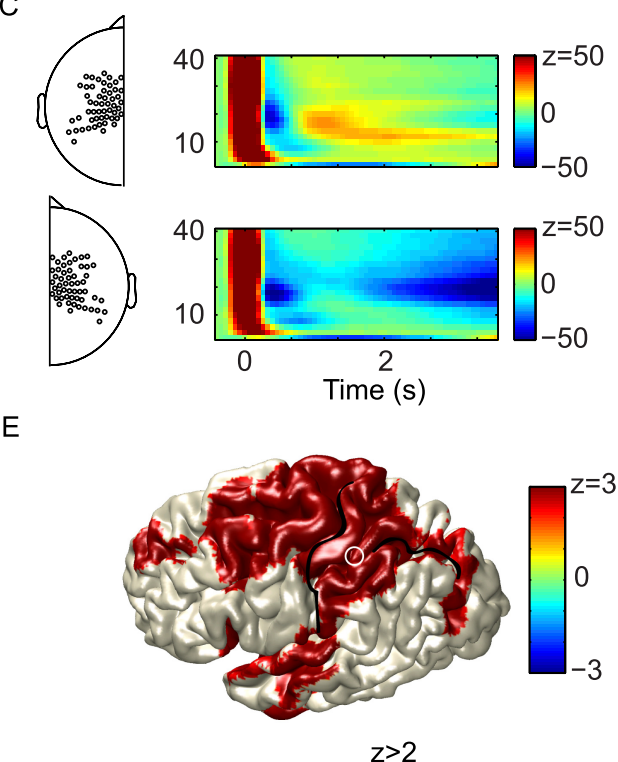

$\mathrm{t}=1 \mathrm{~s} ; \mathrm{z}<-2 ; \mathrm{z}>5$

Figure 4. A, Body-centered lower frequency power modulations during prestimulus and poststimulus phases. Left, Scalp topography shows body-centered suppression for anticipated hand stimulation $(t=-0.3)$. Right, Time-frequency representation averaged across central sensors indicates a second suppression trough during the sensory response interval. $\boldsymbol{B}$, Baseline-corrected scalp topography of beta (top) and alpha (bottom) band modulations directly following right-hand stimulation ( $t=0.3 \mathrm{~s}$ ) and during the delay $(t=0.3-2.7 \mathrm{~s})$. Results are pooled across right-hand stimulation data and mirrored left-hand stimulation data. Convention is such that left hemisphere is contralateral to stimulation, while right hemisphere is contralateral to reach hand. C, TFR of the baseline corrected modulations in left (top) and right (bottom) hemisphere, as measured at central sensors. D, Source reconstruction of body-centered beta-band modulation (1000 ms after stimulus) relative to baseline. M1, Primary motor cortex; S1, primary somatosensory cortex; dPM, dorsal premotor cortex; pIPS, posterior IPS. $E$, Areas showing body-centered modulations (suppression and enhancements) relative to baseline.

reference frame might facilitate potential coordination of effectors.

\section{Automatic transformation into gaze-centered coordinates?}

Another argument for the use of a gaze-centered representation lies in the deployment of spatial attention mediated by the frontoparietal network. Here, we observed a suppression of posterior alpha-band activity $(10 \mathrm{~Hz})$ by tactile stimulation, a rhythm that is closely linked to visuo-spatial attention and excitability of visual areas (Worden et al., 2000; Sauseng et al., 2005; Wyart and TallonBaudry, 2009; Romei et al., 2010; Händel et al., 2011). Cross-modal influences on posterior alpha-band activity have been reported previously (Fu et al., 2001; Bauer et al., 2006, 2012; Trenner et al., 2008; Romei et al., 2009; Banerjee et al., 2011; Gomez-Ramirez et al., 2011; Cappe et al., 2012), but its spatial selectivity across senses has only been addressed once (Buchholz et al., 2011). Here, we show that tactile stimuli induce alpha-band modulations in a reference frame that is linked to visuo-spatial attention mechanisms, reflecting the nonvisible target position relative to gaze. By this cross-modal mechanism, excitability in visual areas could be increased by alpha-band suppression at the veridical retinotopic coordinates, taking current gaze position into account and thereby optimally preparing the system for potential visual input from the same target.

Concurrent with the alpha-band suppression, we observed a transient gazecentered high-gamma-band response in occipital cortex, suggesting a fast transformation of stimulus information into visual areas. This suggests that cross-modal input triggers automatic effects even in "unisensory" visual areas, which is congruent with increasing evidence from studies using nonoscillatory signals (Bueti and Macaluso, 2010; Macaluso and Maravita, 2010). We complement these findings by showing that cross-modal oscillatory signals take the current posture into account, providing the neural basis for spatially specific cross-modal integration, relying on binding across different reference frames. Together, transient effects in the high-gamma-band activity and early modulation in alpha-band activity suggest automatic processes during the early sensory period in this task, which might be independent of motor planning (Van Der Werf et al., 2010). Conversely, the sustained effects during reach planning seem more related to top-down processing and maintenance of target representation, like low-gamma-band activity and beta-band modulations, which will be discussed next.

\section{Low-gamma-band activity supports reach planning in gaze- \\ centered coordinates}

The gaze-centered transient effects in the high-gamma-band activity were followed by sustained synchronization in the lower gamma band in parietofrontal regions, maintaining the target relative to gaze. This drop in frequency may relate to how synchronization comes about in different cortical layers (input vs output layers; see Scheffer-Teixeira et al., 2012). How do these findings relate to previous work on synchronized gamma-band activity during reach planning? First, our findings are in line with monkey physiology, showing spatially tuned low-gamma-band synchronization $(15-50 \mathrm{~Hz})$ in the parietal reach region (PRR) during visually guided reach planning (Scherberger et al., 2005). Similar contralateral gamma-band synchronization has been shown in human visual reaches (Van Der Werf et al., 2010; Hinkley et al., 2011; Joundi et al., 2012). Note, neither of these studies could perform a reference frame analysis because eye position remained straight ahead, aligning body- and gaze-centered representations. Here we report gaze-centered gamma-band activation in human PPC, even for nonvisual targets. The frequency range of the synchronization $(40-60 \mathrm{~Hz})$ is smaller but overlaps with visually guided reaches $(40-90 \mathrm{~Hz})$, as if only the lower 
gamma range is tuned in gaze-centered coordinates during reach planning. Two sources in parietal cortex showed this gazecentered coding: a region medial to IPS, near postcentral sulcus, corresponding to anterior SPL and a source in posterior IPS, overlapping with the observed body-centered beta-band suppression and gaze-centered alpha-band suppression during reach planning. The latter source may be the human analog of monkey PRR.

\section{Coexisting reference frames in spectral channels support reach planning}

Beta-band synchronization has recently been suggested to establish functional connectivity between subregions of parietal cortex during eye-hand coordination. Dean et al. (2012) showed that, in saccade-related area lateral intraparietal area, only those cells firing coherently in the beta range predict saccade reaction times in such tasks. Furthermore, several perceptual studies showed functional coupling within the beta range between distant regions across the fronto-parietal network (for review, see Siegel et al., 2012). In our task, body-centered beta-band modulations encompass rolandic regions, but also regions in PPC that are part of the visual dorsal stream and show gaze-centered low-gammaband activation and alpha-band suppression. Therefore, one could speculate that the beta band establishes functional connectivity between regions locally operating in different reference frames. Previously, we observed body-centered beta-band activity together with gaze-centered gamma-band activity in posterior and occipital regions during the planning of saccades to tactile targets (Buchholz et al., 2011). Here we observed similar spatial selectivities in a reach task. Whereas the spatial selectivity in the beta band suggests a role for relaying somatosensory (bodycentered) information between primary somatosensory, primary motor, and parietal regions, spatial selectivity in the low gamma and alpha bands is implicated in gaze-centered parietal cortical processing. Therefore, beta-band activity may be important for the integration of information across these different spatial formats.

Finally, our results thus highlight the importance of population dynamics to code functional assemblies operating in different reference frames. These results speak to the notion of why investigations of reference frames in firing rates of neurons and neural network simulations lead to more heterogeneous results (Pouget et al., 2002; Blohm et al., 2009; Chang and Snyder, 2010; McGuire and Sabes, 2011). For example, one might observe partially shifting receptive fields when pooling across all action potentials from a neuron, regardless of their phase relationship with the population. However, a different pattern might emerge when separating neurons that spike during specific phases of a population rhythm, as measured by the local field potential. Our results may suggest that different rhythms in the local field potential reflect spatially specific sampling mechanisms within these networks. These mechanisms can be considered flexible enough to implement compound gain fields for different effectors. Future research in monkey physiology should verify this proposal, requiring simultaneous measurements of action potentials and population dynamics.

\section{References}

Andersen RA, Cui H (2009) Intention, Action Planning, and Decision Making in Parietal-Frontal Circuits. Neuron 63:568-583. CrossRef Medline

Astafiev SV, Shulman GL, Stanley CM, Snyder AZ, Van Essen DC, Corbetta M (2003) Functional organization of human intraparietal and frontal cortex for attending, looking, and pointing. J Neurosci 23:4689-4699. Medline
Avillac M, Denève S, Olivier E, Pouget A, Duhamel JR (2005) Reference frames for representing visual and tactile locations in parietal cortex. Nat Neurosci 8:941-949. CrossRef Medline

Banerjee S, Snyder AC, Molholm S, Foxe JJ (2011) Oscillatory alpha-band mechanisms and the deployment of spatial attention to anticipated auditory and visual target locations: supramodal or sensory-specific control mechanisms? J Neurosci 31:9923-9932. CrossRef Medline

Bansal AK, Truccolo W, Vargas-Irwin CE, Donoghue JP (2012) Decoding $3 \mathrm{D}$ reach and grasp from hybrid signals in motor and premotor cortices: spikes, multiunit activity, and local field potentials. J Neurophysiol 107: 1337-1355. CrossRef Medline

Bastiaansen MC, Knösche TR (2000) Tangential derivative mapping of axial MEG applied to event-related desynchronization research. Clin Neurophysiol 111:1300-1305. CrossRef Medline

Bauer M, Oostenveld R, Peeters M, Fries P (2006) Tactile spatial attention enhances gamma-band activity in somatosensory cortex and reduces lowfrequency activity in parieto-occipital areas. J Neurosci 26:490-501. CrossRef Medline

Bauer M, Kennett S, Driver J (2012) Attentional selection of location and modality in vision and touch modulates low-frequency activity in associated sensory cortices. J Neurophysiol 107:2342-2351. CrossRef Medline

Bernier PM, Grafton ST (2010) Human posterior parietal cortex flexibly determines reference frames for reaching based on sensory context. Neuron 68:776-788. CrossRef Medline

Bernier PM, Burle B, Hasbroucq T, Blouin J (2009) Spatio-temporal dynamics of reach-related neural activity for visual and somatosensory targets. Neuroimage 47:1767-1777. CrossRef Medline

Blohm G, Keith GP, Crawford JD (2009) Decoding the cortical transformations for visually guided reaching in 3D space. Cereb Cortex 19:13721393. CrossRef Medline

Breveglieri R, Galletti C, Monaco S, Fattori P (2008) Visual, somatosensory, and bimodal activities in the macaque parietal area PEc. Cereb Cortex 18:806-816. CrossRef Medline

Buchholz VN, Jensen O, Medendorp WP (2011) Multiple reference frames in cortical oscillatory activity during tactile remapping for saccades. J Neurosci 31:16864-16871. CrossRef Medline

Bueti D, Macaluso E (2010) Auditory temporal expectations modulate activity in visual cortex. Neuroimage 51:1168-1183. CrossRef Medline

Cappe C, Thelen A, Romei V, Thut G, Murray MM (2012) Looming signals reveal synergistic principles of multisensory integration. J Neurosci 32: 1171-1182. CrossRef Medline

Chang SW, Snyder LH (2010) Idiosyncratic and systematic aspects of spatial representations in the macaque parietal cortex. Proc Natl Acad Sci U S A 107:7951-7956. CrossRef Medline

Chang SW, Papadimitriou C, Snyder LH (2009) Using a compound gain field to compute a reach plan. Neuron 64:744-755. CrossRef Medline

Conner CR, Ellmore TM, Pieters TA, DiSano MA, Tandon N (2011) Variability of the relationship between electrophysiology and BOLD-fMRI across cortical regions in humans. J Neurosci 31:12855-12865. CrossRef Medline

Crawford JD, Henriques DY, Medendorp WP (2011) Three-dimensional transformations for goal-directed action. Annu Rev Neurosci 34:309331. CrossRef Medline

Darling WG, Seitz RJ, Peltier S, Tellmann L, Butler AJ (2007) Visual cortex activation in kinesthetic guidance of reaching. Exp Brain Res 179:607619. CrossRef Medline

Dean HL, Hagan MA, Pesaran B (2012) Only coherent spiking in posterior parietal cortex coordinates looking and reaching. Neuron 73:829-841. CrossRef Medline

Deneve S, Pouget A (2004) Bayesian multisensory integration and crossmodal spatial links. J Physiol Paris 98:249-258. CrossRef Medline

Fernandez-Ruiz J, Goltz HC, DeSouza JF, Vilis T, Crawford JD (2007) Human parietal "reach region" primarily encodes intrinsic visual direction, not extrinsic movement direction, in a visual motor dissociation task. Cereb Cortex 17:2283-2292. CrossRef Medline

Filimon F, Nelson JD, Huang RS, Sereno MI (2009) Multiple parietal reach regions in humans: cortical representations for visual and proprioceptive feedback during on-line reaching. J Neurosci 29:2961-2971. CrossRef Medline

Fries P (2005) A mechanism for cognitive dynamics: neuronal communication through neuronal coherence. Trends Cogn Sci 9:474-480. CrossRef Medline 
Fu KMG, Foxe JJ, Murray MM, Higgins BA, Javitt DC, Schroeder CE (2001) Attention-dependent suppression of distracter visual input can be crossmodally cued as indexed by anticipatory parieto-occipital alpha-band oscillations. Cogn Brain Res 12:145-152. CrossRef

Gomez-Ramirez M, Kelly SP, Molholm S, Sehatpour P, Schwartz TH, Foxe JJ (2011) Oscillatory sensory selection mechanisms during intersensory attention to rhythmic auditory and visual inputs: a human electrocorticographic investigation. J Neurosci 31:18556-18567. CrossRef Medline

Graziano MS, Hu XT, Gross CG (1997) Visuospatial properties of ventral premotor cortex. J Neurophysiol 77:2268-2292. Medline

Gross J, Kujala J, Hamalainen M, Timmermann L, Schnitzler A, Salmelin R (2001) Dynamic imaging of coherent sources: studying neural interactions in the human brain. Proc Natl Acad Sci U S A 98:694-699. CrossRef Medline

Hagan MA, Dean HL, Pesaran B (2012) Spike-field representations in parietal area LIP during coordinated reach and saccade movements. J Neurophysiol 107:1275-1290. CrossRef Medline

Händel BF, Haarmeier T, Jensen O (2011) Alpha oscillations correlate with the successful inhibition of unattended stimuli. J Cogn Neurosci 23: 2494-2502. CrossRef Medline

Hinkley LB, Nagarajan SS, Dalal SS, Guggisberg AG, Disbrow EA (2011) Cortical temporal dynamics of visually guided behavior. Cereb Cortex 21:519-529. CrossRef Medline

Joundi RA, Brittain JS, Green AL, Aziz TZ, Brown P, Jenkinson N (2012) Oscillatory activity at in the subthalamic nucleus during arm reaching in Parkinson's disease. Exp Neurol 236:319-326. CrossRef Medline

Levy I, Schluppeck D, Heeger DJ, Glimcher PW (2007) Specificity of human cortical areas for reaches and saccades. J Neurosci 27:4687-4696. CrossRef Medline

Liljeström M, Kujala J, Jensen O, Salmelin R (2005) Neuromagnetic localization of rhythmic activity in the human brain: a comparison of three methods. Neuroimage 25:734-745. CrossRef Medline

Logothetis NK (2002) The neural basis of the blood-oxygen-leveldependent functional magnetic resonance imaging signal. Philos Trans $\mathrm{R}$ Soc Lond B Biol Sci 357:1003-1037. CrossRef Medline

Logothetis NK (2007) The ins and outs of fMRI signals. Nat Neurosci 10: 1230-1232. CrossRef Medline

Macaluso E, Maravita A (2010) The representation of space near the body through touch and vision. Neuropsychologia 48:782-795. CrossRef Medline

Magri C, Schridde U, Murayama Y, Panzeri S, Logothetis NK (2012) The amplitude and timing of the BOLD signal reflects the relationship between local field potential power at different frequencies. J Neurosci 32: 1395-1407. CrossRef Medline

Maris E, Oostenveld R (2007) Nonparametric statistical testing of EEG- and MEG-data. J Neurosci Methods 164:177-190. CrossRef Medline

McGuire LM, Sabes PN (2009) Sensory transformations and the use of multiple reference frames for reach planning. Nat Neurosci 12:1056-1061. CrossRef Medline

McGuire LM, Sabes PN (2011) Heterogeneous representations in the superior parietal lobule are common across reaches to visual and proprioceptive targets. J Neurosci 31:6661-6673. CrossRef Medline

Medendorp WP, Goltz HC, Vilis T, Crawford JD (2003) Gaze-centered updating of visual space in human parietal cortex. J Neurosci 23:6209-6214. Medline

Medendorp WP, Kramer GF, Jensen O, Oostenveld R, Schoffelen JM, Fries P (2007) Oscillatory activity in human parietal and occipital cortex shows hemispheric lateralization and memory effects in a delayed double-step saccade task. Cereb Cortex 17:2364-2374. CrossRef Medline

Merriam EP, Genovese CR, Colby CL (2003) Spatial updating in human parietal cortex. Neuron 39:361-373. CrossRef Medline

Mullette-Gillman OA, Cohen YE, Groh JM (2009) Motor-related signals in the intraparietal cortex encode locations in a hybrid, rather than eyecentered reference frame. Cereb Cortex 19:1761-1775. CrossRef Medline

Nichols TE, Holmes AP (2002) Nonparametric permutation tests for functional neuroimaging: a primer with examples. Hum Brain Mapp 15:1-25. CrossRef Medline

Nir Y, Fisch L, Mukamel R, Gelbard-Sagiv H, Arieli A, Fried I, Malach R (2007) Coupling between neuronal firing rate, gamma LFP, and BOLD fMRI is related to interneuronal correlations. Curr Biol 17:1275-1285. CrossRef Medline

Oostenveld R, Fries P, Maris E, Schoffelen JM (2011) FieldTrip: open source software for advanced analysis of MEG, EEG, and invasive electrophysiological data. Comput Intell Neurosci 2011:156869. CrossRef Medline

Percival D, Walden A (1993) Spectral analysis for physical applications: multitaper and conventional univariate techniques. Cambridge, UK: Cambridge UP.

Pesaran B, Nelson MJ, Andersen RA (2006) Dorsal premotor neurons encode the relative position of the hand, eye, and goal during reach planning. Neuron 51:125-134. CrossRef Medline

Pouget A, Deneve S, Duhamel JR (2002) A computational perspective on the neural basis of multisensory spatial representations. Nat Rev Neurosci 3:741-747. CrossRef Medline

Romei V, Murray MM, Cappe C, Thut G (2009) Preperceptual and stimulus-selective enhancement of low-level human visual cortex excitability by sounds. Curr Biol 19:1799-1805. CrossRef Medline

Romei V, Gross J, Thut G (2010) On the role of prestimulus alpha rhythms over occipito-parietal areas in visual input regulation: correlation or causation? J Neurosci 30:8692-8697. CrossRef Medline

Sarlegna FR, Sainburg RL (2009) The roles of vision and proprioception in the planning of reaching movements. In: Progress in motor control (Sternad D, ed.), pp 317-335. Boston: Springer US.

Sauseng P, Klimesch W, Stadler W, Schabus M, Doppelmayr M, Hanslmayr S, Gruber WR, Birbaumer N (2005) A shift of visual spatial attention is selectively associated with human EEG alpha activity. Eur J Neurosci 22:2917-2926. CrossRef Medline

Scheeringa R, Fries P, Petersson KM, Oostenveld R, Grothe I, Norris DG, Hagoort P, Bastiaansen MC (2011) Neuronal dynamics underlying high- and low-frequency EEG oscillations contribute independently to the human BOLD signal. Neuron 69:572-583. CrossRef Medline

Scheffer-Teixeira R, Belchior H, Caixeta FV, Souza BC, Ribeiro S, Tort AB (2012) Theta phase modulates multiple layer-specific oscillations in CA1 region. Cereb Cortex 22:2404-2414. CrossRef Medline

Scherberger H, Jarvis MR, Andersen RA (2005) Cortical local field potential encodes movement intentions in the posterior parietal cortex. Neuron 46:347-354. CrossRef Medline

Siegel M, Donner TH, Engel AK (2012) Spectral fingerprints of large-scale neuronal interactions. Nat Rev Neurosci 13:121-134. CrossRef Medline

Snyder LH, Batista AP, Andersen RA (1997) Coding of intention in the posterior parietal cortex. Nature 386:167-170. CrossRef Medline

Snyder LH, Batista AP, Andersen RA (2000) Saccade-related activity in the parietal reach region. J Neurophysiol 83:1099-1102. Medline

Tagliabue M, McIntyre J (2011) Necessity is the mother of invention: reconstructing missing sensory information in multiple, concurrent reference frames for eye-hand coordination. J Neurosci 31:1397-1409. CrossRef Medline

Trenner MU, Heekeren HR, Bauer M, Rössner K, Wenzel R, Villringer A, Fahle M (2008) What happens in between? Human oscillatory brain activity related to crossmodal spatial cueing. PLoS One 3:e1467. CrossRef Medline

Uhlhaas PJ, Pipa G, Neuenschwander S, Wibral M, Singer W (2011) A newlook at gamma? High- $(>60 \mathrm{~Hz}) \gamma$-band activity in cortical networks: function, mechanisms and impairment. Prog Biophys Mol Biol 105:14-28. CrossRef Medline

Van Der Werf J, Jensen O, Fries P, Medendorp WP (2008) Gamma-band activity in human posterior parietal cortex encodes the motor goal during delayed prosaccades and antisaccades. J Neurosci 28:8397-8405. CrossRef Medline

Van Der Werf J, Jensen O, Fries P, Medendorp WP (2010) Neuronal synchronization in human posterior parietal cortex during reach planning. J Neurosci 30:1402-1412. CrossRef Medline

van Ede F, de Lange F, Jensen O, Maris E (2011) Orienting attention to an upcoming tactile event involves a spatially and temporally specific modulation of sensorimotor alpha- and beta-band oscillations. J Neurosci 31:2016-2024. CrossRef Medline

Womelsdorf T, Fries P (2007) The role of neuronal synchronization in selective attention. Curr Opin Neurobiol 17:154-160. CrossRef Medline

Worden MS, Foxe JJ, Wang N, Simpson GV (2000) Anticipatory biasing of visuospatial attention indexed by retinotopically specific alpha-band electroencephalography increases over occipital cortex. J Neurosci 20:RC63. Medline

Wyart V, Tallon-Baudry C (2009) How ongoing fluctuations in human visual cortex predict perceptual awareness: baseline shift versus decision bias. J Neurosci 29:8715-8725. CrossRef Medline 